\title{
Knowledge of HIV Transmission and Risky Sexual Behavioural Practices Among Selected Adolescents and Young Adults in Lagos, Nigeria
}

\author{
Taiwo Modupe Balogun*, Olawale Dally, Omobolanle Awofala \\ Faculty of Basic Clinical Sciences, Lagos State University Teaching Hospital, Ikeja, Nigeria
}

Email address:

taiwo_modupe@yahoo.com (T. M. Balogun)

${ }^{*}$ Corresponding author

\section{To cite this article:}

Taiwo Modupe Balogun, Olawale Dally, Omobolanle Awofala. Knowledge of HIV Transmission and Risky Sexual Behavioural Practices Among Selected Adolescents and Young Adults in Lagos, Nigeria. International Journal of HIV/AIDS Prevention, Education and Behavioural Science. Vol. 5, No. 2, 2019, pp. 110-114. doi: 10.11648/j.jjhpebs.20190502.15

Received: August 28, 2019; Accepted: September 28, 2019; Published: October 11, 2019

\begin{abstract}
The adolescents and young adults constitute a high risk group for HIV infection due to their common involvement with risky sexual behavioural practices. This study was carried out to assess the basic knowledge of HIV and also identify the risky sexual behavioural practices for infection among studied adolescents and young adults. A self-administered structured questionnaire containing 15 items on demographics, knowledge of HIV/AIDS and risky sexual behavioural practices that may predispose to new infections was completed by respondents and used for data collection. Participation in this survey was voluntary and anonymous among selected adolescents and young adults. One hundred and forty four (144) out of 160 questionnaires that were shared among the adolescents and the youth were completed and returned giving a response rate of $90 \%$. The study population was aged 10-24 years and majority of the respondents $90(62.5 \%)$ were in the age group $21-24$ years while their mean age was $18 \pm 3.9$ years. There was good awareness about HIV and its routes of transmission among respondents $(96 \%)$. The mean age of sexual debut was $15 \pm 5.2$ years. Condom use among the sexually active respondents was low $33(22.9 \%)$. Thirteen $(9.0 \%)$ of the respondents were involved with casual unprotected sex while $59 \%$ of respondents had taken HIV tests. The knowledge of HIV transmission was good while risky sexual behavioural practices for new infections such as early sexual debut, low condom use and low uptake of counseling and testing services with resultant lack of knowledge of personal HIV status, keeping multiple sex partners, were prevalent among studied adolescents and young adults in Lagos, Nigeria.
\end{abstract}

Keywords: HIV Prevention, Youth, Behavioural Change

\section{Introduction}

The Joint United Nations Programme on HIV and AIDS (UNAIDS) estimates that globally, 36.9 million people are living with HIV with new infections being 1.8 million as at 2017. [1]

The World Health Organisation (WHO) reported that currently, there were approximately 1.8 million adolescents between the ages 10 and 19 years living with HIV. [2] Also, it has been reported that an estimated more than $30 \%$ of all new HIV infections globally occur among youth ages 15-25 years. [2] Adolescents and the youth have been found to represent a highly vulnerable population for the acquisition of new HIV infection. [3] The vulnerability of the youth to HIV infection is attributable in part to their common involvement with risky sexual behavioural practices. In Nigeria and Kenya, individuals aged 15-24 years continue to be disproportionately affected by the HIV epidemic and account for $60 \%$ of new infections. [4] Economic need and food insufficiency have been associated with the adoption of unsafe sexual behaviours among women in Zimbabwe. [5] A previous research in Nigeria reported that the prevention of new HIV infection among the youth is feasible through effective peer education programs and training which would improve their knowledge, attitude and sexual behavioural practices. [6] The importance of adolescent sexual and 
reproductive health education as well as behavioural change communication has been emphasized in HIV prevention among the youth. [7] An important step in the prevention of new HIV infections is an increased effort at identifying those at risk of infection through specific sexual risky behavioural practices that promote the spread of the virus. Also, it is reported that an improved multisectoral approach in HIV education with greater participation of school and public library would reduce misconceptions about this scourge thereby preventing further transmission of the virus.[8 ]Abstinence which primarily prevents HIV infection should be perceived as a realistic strategy or intervention for reducing further spread of the virus among the youth. A previous report emphasizes that a major goal of HIV prevention program among the youth is to promote the adoption of abstinence through coherent sexuality education. [9] A previous research found that High school pupils are at high risk of HIV infection yet they continue to engage in risky sexual behavioral practices. [10] The conclusion in this study, was that preventive efforts need to be redirected towards specific risky practices. Also, gender differences would be taken into account with greater attention to religious norms and parental supervision. [10] In a previous study its being suggested that promoting the $\mathrm{ABC}$ approach (abstinence, be faithful, consistent condom use) may reduce the adoption of risky sexual behaviours among the youth in Nigeria. [11] Some researchers found in their study that AIDS education and campaigns that emphasize the seriousness of the epidemic and arouse concern about it could enhance safer sexual practices among the youth in Nigeria. [12] Online sexual health services and interventions were found to increase the knowledge and HIV/STI prevention among homeless youth in Los Angeles. [13] Adequate knowledge is crucial to clearing misconceptions about sexually transmitted diseases including HIV. This would also promote healthy sexual behavioural practices among adolescents and young adults. This study therefore sought to assess the basic knowledge of HIV and also identify risky sexual behavioural practices among the studied youth.

\section{Methods}

This study was community based prospective and longitudinal. Prospective respondents were educated on the purpose of the survey and about the strict confidentiality of their responses. Survey participation was voluntary and anonymous among adolescents and young adults at a youth seminar organized to celebrate the 2016 World AIDS Day in the community. A self-administered structured questionnaire containing 15 items on demographics, knowledge of HIV/AIDS and risky sexual behavioural practices that may predispose to new infections was completed by each respondent. Obtained information was imputed into the computer and statistical analysis was done using Statistical Package for Social Sciences (SPSS) software version 16.0. Results are presented in simple tables of frequencies and percentage.

\section{Results}

One hundred and forty four (144) out of 160 questionnaires that were shared among the adolescents and the youth were completed and returned giving a response rate of $90 \%$.

There were $72(50 \%)$ males and $72(50 \%)$ females with 109 (75.7\%) Christians and 35 (24.3\%) Muslim respondents in the study. The level of education of the respondents comprised $34(23.6 \%)$ university graduates, 56 (38.9\%) undergraduates and 54 (37.5\%) high school pupils as in Table 1.

Table 1. Demographic Characteristics of Respondents.

\begin{tabular}{lll}
\hline Characteristics & $\mathbf{N}=\mathbf{1 4 4}$ & Frequency N (\%) \\
\hline \multirow{2}{*}{ Gender } & Male & $72(50)$ \\
& Female & $72(50)$ \\
Religion & Christainity & $109(75.7)$ \\
& Islam & $35(24.3)$ \\
\multirow{3}{*}{ Level of Education } & High School & $54(37.5)$ \\
& Undergraduates & $56(38.9)$ \\
& University Graduates & $34(23.6)$ \\
\hline
\end{tabular}

The study population was aged 10-24 years and majority of the respondents 90 (62.5\%) were in the age group 21-24 years while their mean age was $18 \pm 3.9$ years as in Table 2 .

Table 2. Age Group Distribution of Respondents.

\begin{tabular}{lll}
\hline Age Group (years) & Number of respondents & Percentage\% \\
\hline $10-14$ & 12 & 8.3 \\
$15-20$ & 42 & 29.2 \\
$21-29$ & 90 & 62.5 \\
Total & 144 & 100 \\
\hline
\end{tabular}

There was good awareness (96\%) about the routes of HIV transmission among the respondents. A few of the respondents $4(2.8 \%)$, believed that HIV infection could be contacted through kissing, hugging, shaking and sitting close to an infected individual as in Table 3 .

Table 3. Respondents' Knowledge of HIV/AIDS.

\begin{tabular}{lll}
\hline \multirow{2}{*}{ Knowledge Variables } & Response & \multicolumn{1}{c}{} \\
\cline { 2 - 3 } & Yes & 142 \\
Is HIV a sexually transmitted infection? & 139 \\
Can HIV be transmitted through contaminated blood? & 98.6 \\
Can infected mother transmit HIV to her unborn child? & 96.5 \\
Can an individual contact HIV through hugging, shaking and sitting with an infected person? & 93.8 \\
Is sharing of sharp objects a route of HIV transmission? & 4.8 \\
Have you ever had sexual intercourse? & 143 \\
\hline
\end{tabular}


The majority $105(72.9 \%)$ of the respondents had had sexual intercourse. The average age of sexual debut among the respondents was $15 \pm 5.2$ years. Sixty five $(45.1 \%)$ of the respondents could not give their precise age of first sexual intercourse or debut but those who did, reported mainly between 10 and 20 years which was $20(13.9 \%)$. First sexual experience in age less than 10 years was $5(3.5 \%)$ while over 20 years was $13(9 \%)$. Forty one $(28.5 \%)$ of the respondents left the question on sexual debut unattended. Twenty two $(15.3 \%)$ respondents admitted that they have sex partners while only $33(22.9 \%)$ used condom for sexual acts. Thirteen (9.0\%) respondents admitted that they practice casual unprotected sex. Eighty five (59\%) of the respondents had taken HIV test and were aware of their status as in Table 4.

Table 4. HIV Risky Sexual Behavioural Practices.

\begin{tabular}{lll}
\hline \multirow{2}{*}{ Variables } & \multicolumn{2}{l}{ Response $\mathbf{n = 1 4 4}$} \\
\cline { 2 - 3 } & Yes & $\mathbf{\%}$ \\
\hline Have you ever had sexual intercourse? & 105 & 72.9 \\
Age of sexual debut at what age did you first have & & \\
sexual intercourse? & & \\
Below age 10 & 5 & 3.5 \\
Between age 10 and 20 & 20 & 13.9 \\
Above age 20 & 13 & 9.0 \\
Can't say & 65 & 45.1 \\
Do you have sex partners? & 20 & 13.9 \\
Mean Age of sexual debut: 15 ( \pm 5.2) year & & \\
Do you use condoms for sexual acts & 33 & 22.9 \\
Do you know your HIV status? & 85 & 59 \\
Do you practice casual unprotected sex? & 13 & 9.0 \\
\hline
\end{tabular}

\section{Discussion}

Our study was about the basic HIV knowledge and risky sexual behavioural practices that may predispose to new infections among adolescents and young adults in Nigeria. We observed that our respondents had an overall good knowledge (96\%) about routes of HIV transmission. This finding is consistent with previous research reports $[9,14$, 15] but at variance with another with low level of awareness of HIV. [16] Awareness about HIV has been associated with gender, level of formal education as well as the degree of urbanization of residential areas. [16] The observation in our survey of a few respondents $4(2.8 \%)$ having misconceptions that HIV could be acquired through casual contacts such as; kissing, hugging, shaking hands, sitting close to or sharing household utensils with an infected individual is much lower than in a previous finding of $53.7 \%$ with such erroneous beliefs among the youth. [8] The differences could be as a result of differing levels of education and therefore of HIV knowledge. We found that majority 105 (72.9\%) of the respondents in our survey had had sexual intercourse. This finding is comparable with previous reports of $80.7 \%$ [16], $70.6 \%$ [17], but at variance with another report of $12 \%$ [9] among the youth in previous studies in Nigeria. The differences in the sexual experiences among the youth in the various surveys may be due to the location and level of urbanization of respondents' residence. Sexual abstinence primarily prevents HIV and is reportedly a realistic strategy for reducing further spread of the virus and new infections among the youth. [9] However, the sexual abstinence of the youth is reportedly influenced by multiple factors that need to be put into consideration when measuring the effectiveness of interventions targeted at this practice. Some of such factors that have been significantly associated with sexual abstinence include; living arrangements, types of occupation, alcohol use, self-esteem, some leisure activities, perceived self efficacy to refuse sex and negative perception of peers who engage in sexual behaviours [9, 17] Other documented major predictors of sexual abstinence in previous researches are; being a female, not having a boyfriend or girlfriend, not using alcohol, having positive attitude towards abstinence, living with parents or other relatives, high self esteem and reading of novels at leisure times. [9, 17] The mean age of sexual debut in our survey was $15 \pm 5.2$ years. This finding is comparable with a previous report of $14.8 \pm 2.0$ years.[18] but a little higher than $12 \pm 2.8$ years. [19] from another survey in Nigeria. The differences in age of sexual debut among the studied youth may be in the differences in the locations of the various surveys. Early age at first sex is reportedly a sexual risk for HIV infection. [20] A previous study revealed that the timing of sexual debut by men was attributed to peer pressure while several women felt pressured by their male partner which underscores the need for gender transformative HIV interventions. [21] Younger age of sexual debut is a high risk sexual behavioural practice for HIV infection and also poses health risk for both young men and women. Therefore, delaying sexual debut is an important HIV prevention strategy. The level of education, wealth status and gender have been reported to influence age of first sex among the youth; the less educated and the poor female youth are more likely to initiate sex at an earlier age. [20] It has been found in Nigeria and Senegal, that poor female youth report earlier first sex than their wealthier peers. [20] Young people who initiate sex at an early age are reportedly sexually active for a longer period of time, and are more likely to have multiple sex partners and also have an increased risk of contracting HIV. [22-24]

Delaying initiation of sexual intercourse has thus become a prime goal for interventions in Sub Saharan Africa [25, 26]. Therefore, a major goal of HIV prevention program among young people should be to delay sexual debut. Risk of sexual debut has been reportedly reduced among young men in communities where HIV related messages were discussed at Parents Teachers Association meetings.[27] The same was found in communities where abstinence was the primary AIDS prevention message conveyed to the youth and where AIDS deaths were publicly acknowledged. [27] In some parts of Africa, male circumcision has been reported to hasten sexual initiation while in others; it has been associated with a delay. [28] Some 20 (13.9\%) single youth in our survey admitted to have had sex partners while 33 (22.9\%) used condom for sexual acts. The observation of low condom use among sexually active youth in our current survey is 
consistent with findings in previous studies in Nigeria. [2931] Appropriate and consistent use of condom still remains an effective approach to HIV/AIDS intervention. Older age at first sex has been associated with the use of condom and other methods of contraception. [17] Risky sexual behavioural practices such as unprotected sex, low and inconsistent use of a condom during sexual intercourse, have been associated with HIV infection. Healthy sexual decision making of the youth is therefore very important in the prevention of new HIV infections. Knowledge of correct condom use, ever undergone HIV test, knowledge of the mode of HIV transmission, male gender, alcohol use, marijuana use, age, urban or rural place of residence, region, education, wealth index, religious affiliation, exposure to mass media and total life-time number of sex partners were associated with sexual experience and use of protective measures. [18, 30-33] Also, high risk perception of HIV acquisition among the youth has been shown to improve behavioural change and the likelihood of condom use. [34, 35]. However, frequency of oral sexual behaviour has been identified as a negative predictor of intent to use condom. [32] Living in the southern regions of Nigeria was also found to promote the use of condom among the youth. [31] This finding may be attributable to the high level of education and therefore HIV knowledge in this part of Nigeria. Nine percent of the respondents in our survey, practiced casual unprotected sex which is a risky sexual behavioural practice and has been associated with HIV infection. This finding is comparable with a previous report where $9.1 \%$ of youth had recent sexual intercourse with casual partners. [16] A previous research in Nigeria found out that unprotected heterosexual intercourse was common among HIV counseling clients, pointing to the need to step up HIV prevention programs through emphasis on behavioural change. [36] Fifty nine percent of respondents had taken HIV test and were aware of their status while forty one hadn't in our survey. This finding is at variance with a previous report in a survey where $3.34 \%$ of youth had conducted HIV test. [15] The marked difference could be due to differences in the level of urbanization of the location of the surveys. Ever undergone HIV test and the knowledge of one's status have been found to improve consistent condom use during sexual intercourse. [31, 33]

\section{Conclusion}

The knowledge of HIV transmission was good while risky sexual behavioural practices for new infections such as; early sexual debut, low condom use, and low uptake of counseling and testing services with low knowledge of personal status were also prevalent among studied adolescents and young adults in our survey. We recommend that HIV Prevention Programmes targeted at the youth give necessary information to improve on the level of risk perception of infection as a result of involvement with specific risky sexual behavioural practices so as to enhance positive beavioural change. Also, young people should be encouraged to take up HIV tests so they know their status as this would enhance the use of sexual protective devices and reduce further HIV transmission and therefore new infections among the unmarried youth.

\section{References}

[1] UNAIDS. Global HIV and AIDS Statistics-2018 fact sheet. Available at www.unaids.org/en/resources/fact sheet. accessed 10 July 2019.

[2] WHO. Maternal, newborn, child and adolescent health. HIV $\begin{array}{llll}\text { and } & \text { youth. } & 2018 & \text { Available }\end{array}$ http://www.who.int/maternal_child_adolescents_health/en/ accessed 10 July, 2019.

[3] Rudy BJ, Kapogiannis BG, Lally MA, Gray GE, Bekker LG, Krogstad et al. Youth-Specific Considerations in the Development of PrEP, Microbicide and Vaccine Research Trials J Acquir Immune Defic Syndr. 2010; 54 (Suppl 1): S31-S42.

[4] UNAIDS. Children and AIDS: Third Stock Taking Reports 2008. Geneva: 2009. (March 25, 2011) Available at http://www.data.unaids.org/pub/reports/2008. Accessed 16 July 2019.

[5] Pascoe SJ, Langhaug LF, Mavhu W, Hargreaves J, Jaffar S, Hayes R et al. Poverty, food insufficiency and HIV infection and sexual behaviour among young rural Zimbabwean women. PLoSOne. 2015 27; 10 (1): e0115290.

[6] Abu-Saeed MB, Abu-Saeed K. Attitudinal Changes Using Peer Education Training in the Prevention of HIV/AIDS: A Case Study of Youths in North Central Nigeria. Adv Pharm Bull. 2013; 3 (1): 45-50.

[7] Isiugo-Abanihe UC, Erinosho O, Ushie B, Aderinto A, Sunmola G, Joseph R. Age of sexual debut and patterns of sexual behaviour in two local government areas in southern Nigeria. Afr J Reprod Health. 2012; 16 (4): 81-94.

[8] Bamise OF, Bamise CT, Adedigba MA. Knowledge of HIV/AIDS among secondary school adolescents in Osun state, Nigeria. Niger J Clin Pract 2011; 14: 338-44.

[9] Oladepo O, Fayemi MM. Perceptions about sexual abstinence and knowledge of HIV/AIDS prevention among in-school adolescents in a western Nigerian city. BMC Public Health. 2011; 11: 304.

[10] Frank S, Esterhuizen T, Jinabhai CC, Sullivan K, Taylor M. Risky sexual behaviours of high- school pupils in an era of HIV and AIDS. S Afr Med J. 2008; 98 (5): 394-8.

[11] Etukumana EA, Thacher TD, Sagay AS. HIV risk factors among pregnant women in a rural Nigerian hospital. West Indian Med J. 2010; 59 (4): 424-8.

[12] Oyeyemi YA, Abdulkarim A, Oyeyemi BO The influence of knowledge and sociodemographics on AIDS perception and sexual practices among secondary school students in Nigeria. Afr Health Sci. 2011 August; 11 (Suppl 1): S67-S76.

[13] Young S D, Rice E. Online Social Networking Technologies, HIV Knowledge, and Sexual Risk and Testing Behaviors Among Homeless Youth. AIDS and Behavior 2011, 15 (2), 253-260. 
[14] Adedimeji AA., Omololu F O., Odutolu O. HIV Risk Perception and Constraints to Protective Behaviour among Young Slum Dwellers in Ibadan, Nigeria J Health Popul Nutr. 2007; 25 (2): 146-157.

[15] Oyekale AS, Oyekale TO. Application of health belief model for promoting behaviour change among Nigerian single youth. Afr J Reprod Health. 2010; 14 (2): 63-75.

[16] Owoaje ET, Adebiyi AO, Adebayo MA. Sexual risk behaviours and HIV knowledge of migrant farm workers in a rural community in Nigeria. Afr J Med Med Sci. 2011; 40 (1): 75-84.

[17] Sangowawa AO, Adebiyi AO. Factors associated with sexual abstinence among out-of-school females in a transitional town in Oyo State, South-Western Nigeria. Health Care Women Int. 2013; 34 (10): 917-32.

[18] Folayan MO, Odetoyinbo M, Harrison A. Differences in use of contraception by age, sex and HIV status of 10-19-year-old adolescents in Nigeria International Journal of Adolescent Medicine and Health Int J Adolesc Med Health. 2015 Nov 10. pii:/j/ijamh.ahead-of-print/ijamh-2015-0059/ijamh-20150059.xm

[19] Duru CB, Nnebue CC, Uwakwe KA, Obi-Okaro AC, Diwe $\mathrm{KC}$, Chineke $\mathrm{HN}$ et al. Sexual behaviours and contraceptive use among female secondary school adolescents in a rural town in Rivers state, South-south Nigeria. Niger J Med. 2015; 24 (1): 17-27.

[20] Speizer IS, Fotso JC, Christophe JJ, Saad A, Otai J. Timing and Circumstances of First Sex among Female and Male Youth From Select Urban Areas of Nigeria, Kenya, and Senegal. Journal of Adolescent Health 2013; 53 (5): 609-616.

[21] Stern E, Cooper D. Experiences and conceptualizations of sexual debut from the narratives of South African men and women in the context of HIV/AIDS. Afr J AIDS Res. 2014; 13 (2): 121-31.

[22] Akwara PA, Madise NJ, Hinde A, Perception of risk of HIV/AIDS and sexual behaviour in Kenya. Journal of Biosocial Science, 2003, 35 (3): 385-411.

[23] Pettifor A, Macphail C, Rees H, Cohen M. HIV and Sexual Behavior among Young South Africans: A National Survey of 15-24-Year-Olds, Johannesburg, South Africa: Reproductive Health Research Unit, University of Witwatersrand, 2004. Sex Transm Dis. 2008; 35 (10): 843-4.

[24] Odu OO, Asekun-Olarinmoye EO, Bamidele JO, Egbewale $\mathrm{BE}$, Amusan OA, Olowu AO. Knowledge, attitudes to HIV/AIDS and sexual behaviour of students in a tertiary institution in south-western Nigeria, European Journal of Contraception \& Reproductive Health, 2008, 13 (1): 90-96.
[25] Gregson S, Zhuwau T, Anderson RM, Chandiwana SK. Is there evidence for behaviour change in response to AIDS in rural Zimbabwe? Social Science \& Medicine, 1998, 46 (3): 321-330.

[26] Macintyre K, Brown L, Sosler S. "It's not what you know, but who you knew": examining the relationship between behavior change and AIDS mortality in Africa, AIDS Education and Prevention, 2001, 13 (2): 160-174.

[27] Tenkorang E Y, Maticka-Tyndale E. Individual- and Community-Level Influences on the Timing of Sexual Debut Among Youth in Nyanza, Kenya. International Perspectives on Sexual and Reproductive Health. 2014; 40 (2): 68-78.

[28] Crossland N, Hadden WC, Vargas WE, Valadez JJ, Jeffery C. Sexual and Reproductive Health Among Ugandan Youth: 2003-04 to 2012. J Adolesc Health. 2015; 57 (4): 393-8.

[29] Oyeyemi A, Oyeyemi B. Young adults and AIDS epidemics: their perception awareness information sources and sexual practices. East Afr J Public Health. 2012; 9 (1): 13-8.

[30] Oyediran KA, Feyisetan OI, AkpanT. Predictors of Condomuse among Young Never-married Males in Nigeria. J Health Popul Nutr. 2011; 29 (3): 273-285.

[31] Adebowale SA, Ajiboye BV, Arulogun O. Patterns and correlates of condom use among unmarried male youths in Nigeria: NDHS 2008. Afr J Reprod Health. 2013; 17 (3): 14959.

[32] Essien EJ,. Ogungbade GO,. Kamiru HN, Ekong E, Ward D, Holmes L. Emerging socio-demographic and lifestyle predictors of intention to use condom in Human Immunodeficiency Virus (HIV) intervention among Uniformed Services Personnel. Mil Med. 2006; 171 (10): 1027-1034.

[33] Strömdahl S, Onigbanjo W A, Eziefule B, Emmanuel G, Iwuagwu S, Anene $\mathrm{O}$ et al. Associations of consistent condom use among men who have sex with men in Abuja, Nigeria. AIDS Res Hum Retroviruses. 2012; 28 (12): 1756-62.

[34] Adegun PT, Adegoke SA, Solomon OS, Ade-Ojo IP. Perception of personal risk of acquiring human immunodeficiency viral infection/acquired immune deficiency syndrome among people attending outpatient clinics in a teaching hospital of Nigeria. Indian J Public Health. 2013; 57 (2): 96-9.

[35] Adebiyi AO, Asuzu MC. Condom use amongst out of school youths in a local government area in Nigeria. Afr Health Sci. 2009; 9 (2): 92-97.

[36] Olowookere SA, Adeleke NA, Fatiregun A A, Abioye-Kuteyi EA. Pattern of condom use among clients at a Nigerian HIV Counseling and Testing Centre. BMC Res Notes 2013; 6: 289293. 